\title{
Підвищення точності вимірювання датчика рівня палива за допомогою сигналізатора рівня палива
}

\author{
В.М. Зубко ${ }^{1}$, С.П. Соколік, М.Р. Шевченко \\ Сумський національний аграрний університет (м. Суми, Україна) \\ email: ${ }^{1}$ zubkovladislav@ukr.net
}

\begin{abstract}
В статті було проведено аналіз фракторів, що впливають на точність показань датчиків рівня палива. Розглянуті характеристики та конструктивні особливості датчиків рівня палива різних типів. На сучасних автомобілях як датчики рівня палива використовуються потенціометричні датчики переміщення. Перевагами таких датчиків $\epsilon$ простота конструкції, надійність вимірювань, низька вартість. До недоліків можна віднести наявність рухомих контактів, схильних з часом зносу і окисленню.

Проаналізовано вплив теплового розширення пального на роботу паливних датчиків. Підвищення температури палива призводить до збільшення його об'єму, що в свою чергу може спричинити пошкодження баків та суміжних деталей а також збільшує похибку показань датчиків рівня палива. Таке явище з методом заправки на підприємстві несе такі наслідки: деформація пластмасових баків; псування клапану кришки заливної горловини; втрата палива, затискання, згин, пошкодження ізоляції при деформуванні пластмасових баків; зменшення якості контролю за кількістю палива в баці GPS пристроями; розрив алюмінієвих, металевих баків.

Запропоновано схему сигналізатора рівня палива. Ця схема $є$ оптимальною і не вимагає додаткового втручання в паливну систему. Сигналізатор рівня палива призначений для заправки палива до одного й того ж рівня при кожній заправці з урахуванням об'єму для розширення дизпалива. Його спрацювання залежить від датчика рівня палива, в якому, як зазначено вище, кожному значенню рівня палива в баку відповідає певний сигнал датчика і зміна напруги на потенціометрі. Діапазон напруги датчика рівня палива від 0 до 12 В.
\end{abstract}

Ключові слова: паливо, витрати палива, датчик рівня палива, точність вимірювання, теплове розширення, сигналізатор рівня палива.

Постановка проблеми в загальному вигляді. Паливо - одна з головних статей витрат на транспорт, до того ж паливо найчастіше $є$ головним об'єктом різних махінацій. Подібні обставини і роблять використання систем контролю над витратою палива найбільш актуальним, оскільки саме вони здатні захистити вас від труднощів, пов'язаних із надмірною витратою палива. Проблеми, пов'язані з урахуванням витрати палива, мають кілька рішень, але вибір прийнятного варіанту повинен бути тільки індивідуальним, відповідно до вимог систем контролю.

Робота датчика рівня палива побудована за принципом - кожному значенню рівня палива в баку відповідає певний сигнал датчика. Але сучасні паливні баки мають складну фрорму (адаптовані до простору кузова автомобіля), а залежність рівня палива від його залишку в баку носить нелінійний характер.

Крім цього, конструкція датчика рівня палива така, що паливо повинне опуститися нижче певного рівня, перш ніж поплавок почне опускатися. Покажчик рівня палива деякий час показує повний бак, і тільки потім починає опускатися. У підсумку всі датчики рівня палива видають деяку похибку у вимірі правильної величини.
Залежно від виду вихідного сигналу розрізняють датчики з аналоговим і цифровим сигналом. Аналоговий вихідний сигнал являє собою зміну напруги на потенціометрі. Аналогові датчики мають високу похибку вимірювань, тому в даний час майже не використовуються.

У цифровому датчику мікропроцесор перетворює аналоговий сигнал в «цифру», а також здійснює коригування і вирівнювання похибки вимірювань, викликаної коливанням рівня палива i геометрією паливного бака. Цифрові датчики рівня палива забезпечують досить високу точність вимірювань [1].

Також на роботу датчиків рівня палива істотно впливає таке явище, як теплове розширення рідини. Підвищення температури палива призводить до збільшення його об'єму, що в свою чергу може спричинити пошкодження баків та суміжних деталей а також збільшує похибку показань датчиків рівня палива.

Аналіз останніх досліджень і публікацій. GPS-контроль витрати палива здійснюється за допомогою декількох методів, які відрізняються точністю вимірювання, так і результатами і вартістю такого контролю [2]. 
Найпростішим і найдешевшим, але при цьому найменш точним, методом для контролю витрат палива $є$ метод, що не вимагає ніякого втручання безпосередньо в паливну систему.

Облік витрат палива в цьому методі здійснюється за таким принципом: в диспетчерській програмі встановлюється нормативне значення кількості використаного пального для кожного конкретного автомобіля, обладнаного системою GPS-моніторингу. У програмі автоматично відбувається множення значення витрат палива на реальний пробіг автомобіля, який визначається за даними зі супутникової системи. Таким же чином розраховується і витрата пального, використаного за конкретний проміжок часу.

Існують і більш точні методи контролю палива. Приміром, підключення до вже встановленого GPS-обладнання бортового типу датчика рівня палива. Даний метод має також декілька інших варіантів, які відрізняються точністю і вартістю вимірювання. Один з найдоступніших варіантів - підключення до штатного датчика палива на автомобілі без змін паливної системи, але таке підключення дасть сильну похибку. На автомобілі вітчизняного виробництва з уже встановленим механічним поплавковим датчиком похибка становитиме близько 20-25\%, а на імпортних сучасних машинах - не більше 7-15\%.

Має значення і знос самого контролера, що і $€$ головним недоліком цього методу. Ще одним досить вагомим мінусом $є$ те, що під час експлуатації початкові неточні показники будуть спотворюватися ще сильніше. Попри це установка даної системи контролю витрати пального дозволить із точністю виконати облік витрат палива, а також відобразити час і місце всіх скоєних заправок i можливих зливів палива в певних транспортних засобах. Головним плюсом даного методу є можливість вимірювання рівня не тільки бензину, але і дизпалива [3].

Датчик рівня палива в складі паливної системи служить для визначення рівня палива в паливному баку автомобіля. Датчик встановлюється безпосередньо в паливному баку. Датчик вимірює рівень палива в баку, передає значення в GPS термінал, термінал «запам'ятовує» своє місце розташування і передає на сервер інформацію за рівнем палива в баку і розташуванню. Сервер зберігає всю прийняту інформацію в базі даних і дозволяє відобразити на комп'ютері витрати палива на 100 км, за 1 годину, за вказаний проміжок часу або в будь-якій точці і будь-який час [4].

Мета досліджень. Метою досліджень є дослідження факторів, що впливають на роботу обладнання для контролю витрат пального автомобілів та тракторів, зокрема проблем, пов'язаних 3 тепловим розширенням палива, а також обґрунтування конструктивної схеми сигналізатора рівня палива.

Викладення основного матеріалу. Датчик рівня палива використовується спільно 3 покажчиком рівня палива, який у свою чергу розташовується на панелі приладів.

На сучасних автомобілях як датчик рівня палива використовується потенціометричний датчик переміщення. Перевагами потенціометричного датчика $€$ простота конструкції, надійність вимірювань, низька вартість. До недоліків можна віднести наявність рухомих контактів, схильних 3 часом зносу і окисленню.

У паливній системі автомобіля застосовуються потенціометричні датчики двох типів - важільні і трубчасті [5]. Чутливим елементом обох типів датчиків $€$ поплавок, який завжди знаходиться на поверхні палива. Поплавок виготовляється $з$ пінопласту, порожнистої пластмаси або тонкого металу.

Важільний датчик рівня палива(рис 1) - поплавок з'єднаний металевим важелем із рухомим контактом потенціометра. Сам потенціометр являє собою електричний пристрій, робота якого полягає у створенні опору току. Потенціометр виконаний у вигляді сектора, на який нанесені смуги резистивного матеріалу.

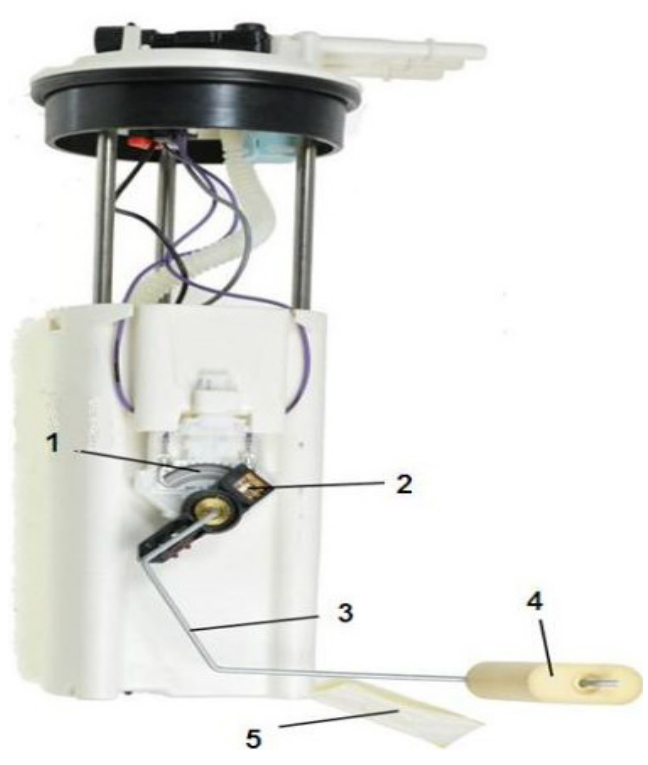

Рис. 1 Пристрій датчика рівня палива важільного типу: 1 - потенціометр; 2 - рухливий контакт бігунок); 3 - металевий важіль; 4 - поплавок; 5 - паливо вловлювач.

Датчик рівня палива трубчастого типу (рис. 2) - включає трубку, у якій по направляючої переміщається поплавок. Паралельно направляючої розташовані дроти опорів. На них замикаються 
контактні кільця на поплавкові. Основною перевагою датчика трубчастого типу є стійкість до коливань рівня палива при зміні положення автомобіля в русі (поворот, підйом, спуск і т.д.). Датчик має обмеження у використанні, обумовлені геометричними параметрами паливного бака.

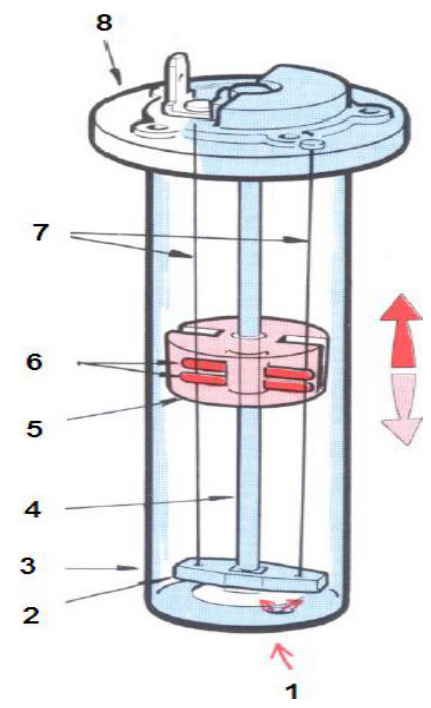

Рис. 2. Пристрій датчика рівня палива трубчастого типу: 1 - отвір для доступу палива; 2 - ізолююча пластина; 3 - захисна трубка; 4 - напря-

мна стійка; 5 - поплавок; 6 - контактні кільця;

7 - провід опору; 8 - кріпильний фрланець.

В зв'язку з обліком дизельного палива на підприємстві, заправки транспортних засобів проводять до горловини баку. Цей метод дає змогу щораз заливати паливо до того ж рівня, що й кожен з попередніх чи наступних. Таким чином списання и визначення залишків на кінець зміни розраховується за простою арифметичною формулою (1):

$$
\mathrm{V}_{\text {зал }}=\mathrm{V}_{\text {б }}-\mathrm{V}_{\text {зап }}
$$

де, $\mathrm{V}_{\text {зал }}$ - об'єм залишку, л; $\mathrm{V}_{б}$ - об'єм баку, л; $\mathrm{V}_{\text {зап }}$ - об'єм заправки, л

Такий метод за своєю специфікою має й негативні властивості. Якщо взяти до уваги металеві чи алюмінієві баки, то для з'єднання внутрішньої порожнини з навколишнім середовищем передбачено клапан, який знаходиться в кришці заливної горловини. Призначений він для зрівноваження надлишкового тиску або розрідження $з$ атмосферним тиском.

При тиску в баці, який виникає в зв'язку з розширенням палива зі збільшенням температури, клапан не в змозі пропустити паливо, так як його густина в сотні раз більше за густину повітря. В наслідок цього розширене паливо псує кришку и виходить на зовні.
Якщо взяти пластмасові баки, то при надлишковому тиску чи розрідженні, зазвичай деформується сам бак. Конструктивні особливості цих ємностей передбачає сопунпризначений для з'єднання внутрішньої порожнини з атмосферою, який завжди забруднюється і не виконує своєї фрункції.

Сигналізатор рівня палива призначений для заправки палива до одного й того ж рівня при кожній заправці з урахуванням об'єму для розширення дизпалива. Його спрацювання залежить від датчика рівня палива, в якому, як зазначено вище, кожному значенню рівня палива в баку відповідає певний сигнал датчика і зміна напруги на потенціометрі. Діапазон напруги датчика рівня палива від 0 до 12 В. Припустимо, що пустий бакце $0 \mathrm{~B}$, повний - $12 \mathrm{~B}$.

Налаштування сигналізатора для вмикання потрібно підібрати вхідну напругу, яка буде відповідати певному рівні палива.

Теплове розширення - зміна геометричних розмірів (об'єму) тіла внаслідок зміни його температури.

Ця властивість характерна для всіх речовин. Коли речовина нагрівається, її частинки починають інтенсивніше рухатися, що приводить до збільшення середніх відстаней між ними.

Ступінь розширення речовини віднесений до зміни температури називається коефіцієнтом теплового розширення, що в цілому залежить від температури. В таблиці 1 приведено приклад коефіцієнта об'ємного розширення дизпалива в залежності густини при зміні температури на $1^{\circ} \mathrm{C}$.

Густина приведена при температурі $20^{\circ} \mathrm{C}$.

Згідно ISO 3675 :

- густина літнього дизельного палива - 860 кг/м³; - густина зимнього дизельного палива - 840 кг/м³; - густина арктичного дизельного палива - 830 кг/м³.

Розрахунок об'ємного розширення проводитимемо на прикладі трактора NewHolland T8.3903 об'ємом бака 637л. В експлуатаційному режимі, а також під впливом сонячних променів дизпаливо в баці нагрівається приблизно до $50^{\circ} \mathrm{C}$. Зранку при заправці температура близько $19-21^{\circ} \mathrm{C}$. Для розрахунків візьмемо середнє значення - $20^{\circ} \mathrm{C}$.

Густину палива, в даному випадку беремо 3 таблиці. Якщо температура буде іншою, то і густина зміниться.

Визначити при розширенні яку можна за формулою 2 :

$$
\mathrm{R}_{20^{\circ} \mathrm{C}}=\mathrm{R}_{\mathrm{t}}+\mathrm{g}(\mathrm{t}-20)
$$

де $\mathrm{R}_{20^{\circ} \mathrm{C}}$ - густина при $20^{\circ} \mathrm{C}, к г / \mathrm{cm}^{3} ; \mathrm{R}_{\mathrm{t}}$ - шукана гу-

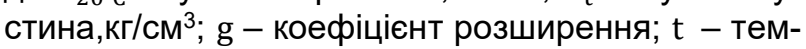
пература, ${ }^{\circ} \mathrm{C}$.

Якщо об'єм баку 637л при $20^{\circ} \mathrm{C}$ з густиною $860 \mathrm{kг} / \mathrm{M}^{3}$, то коефріцієнт розширення складатиме 0,00079, згідно таблиці 1. Розрахунок об'єму 
дизпалива при збільшенні температури на $1^{\circ} \mathrm{C}$ складатиме:

$$
\mathrm{V}_{2}=\mathrm{V}_{1} \beta+\mathrm{V}_{1}
$$

де $\mathrm{V}_{2}$ - об'єм палива після розширення, л; $\mathrm{V}_{1}$ початковийоб'єм, л; $\beta$ - коефіцієнт розширення;

$$
\mathrm{V}_{2}=637 * 0,00079+637=637,503 \text { л. }
$$

Отже, кінцевий об'єм складає 637,503 л. Ми бачимо, що зміна лише на $1^{\circ} \mathrm{C}$, склала розширення в 0,503 л.

Таблиця 1. Температурний коефіцієнт

\begin{tabular}{|c|c|c|c|c|c|}
\hline$\rho, \mathrm{\kappa} / \mathrm{cm}^{3}$ & $\beta, 1 /{ }^{\circ} \mathrm{C}$ & $\mathrm{K} / \mathrm{cm}^{3}$ & $\beta, 1 /{ }^{\circ} \mathrm{C}$ & $\rho$, кг/см ${ }^{3}$ & $\beta, 1 /{ }^{\circ} \mathrm{C}$ \\
\hline $\begin{array}{c}690,0- \\
699,9\end{array}$ & 0,00130 & & 0,00094 & & ,00067 \\
\hline $\begin{array}{c}700,0- \\
709,9\end{array}$ & 0,00126 & $\begin{array}{c}810,0- \\
819,9\end{array}$ & 0,00092 & $\begin{array}{c}920,0- \\
929,9\end{array}$ & 0,00065 \\
\hline $\begin{array}{c}710,0- \\
719,9\end{array}$ & 0,00123 & $\begin{array}{r}820 \\
82\end{array}$ & 089 & \begin{tabular}{|c|}
$930,0-$ \\
939,9
\end{tabular} & 0063 \\
\hline $\begin{array}{c}720,0- \\
729,9\end{array}$ & 9 & $\begin{array}{c}830,0- \\
839,9\end{array}$ & 86 & $\begin{array}{c}940,0- \\
949,9\end{array}$ & 061 \\
\hline $\begin{array}{c}730,0- \\
739,9\end{array}$ & 6 & $\begin{array}{c}840,0- \\
849,9\end{array}$ & 84 & $\begin{array}{c}950,0- \\
959,9\end{array}$ & 059 \\
\hline $\begin{array}{c}740,0- \\
749,9\end{array}$ & 3 & $\begin{array}{c}850,0 \text { - } \\
859,9\end{array}$ & 81 & $\begin{array}{c}960,0- \\
969,9\end{array}$ & 057 \\
\hline $\begin{array}{c}750,0- \\
759,9\end{array}$ & 9 & $\begin{array}{c}860,0- \\
869,9\end{array}$ & 079 & $\begin{array}{c}970,0- \\
979,9\end{array}$ & 0055 \\
\hline $\begin{array}{c}760,0- \\
769,9\end{array}$ & 0,00106 & $\begin{array}{c}870,0- \\
879,9\end{array}$ & 0,00076 & $\begin{array}{c}980,0- \\
989,9\end{array}$ & 0,00053 \\
\hline $\begin{array}{c}770,0- \\
779,9\end{array}$ & 0,00103 & $\begin{array}{c}880,0 \text { - } \\
889,9 \\
\end{array}$ & ,00074 & $\begin{array}{c}990,0- \\
999,9\end{array}$ & 0,00052 \\
\hline $\begin{array}{c}780,0- \\
789,9\end{array}$ & 0,00100 & $\begin{array}{c}890,0- \\
899,9\end{array}$ & 0,00072 & - & - \\
\hline $\begin{array}{c}790,0- \\
799,9\end{array}$ & 0,00097 & $\begin{array}{c}900,0- \\
909,9\end{array}$ & 0,00070 & - & - \\
\hline
\end{tabular}
об'ємного розширення

Якщо провести розрахунок на зміну температури в $30^{\circ} \mathrm{C}$, то отримаємо данні, приведені в таблиці 2. Останнім розрахунком буде визначення різниці кінцевого і початкового об'ємів, за формулою 4:

$$
\mathrm{V}_{\text {розш }}=\mathrm{V}_{50^{\circ} \mathrm{C}}-\mathrm{V}_{20^{\circ} \mathrm{C}}
$$

де $\mathrm{V}_{\text {розш }}$ - об'єм розширення, л; $\mathrm{V}_{50^{\circ} \mathrm{C}}$ - об'єм при $50^{\circ} \mathrm{C}$, л; $\mathrm{V}_{20^{\circ} \mathrm{C}}-$ об'єм при $20^{\circ} \mathrm{C}$, л;

$$
\mathrm{V}_{\text {розш }}=652,271-637,000=15,271 \Omega
$$

Згідно розрахунків зміна температури в $30^{\circ} \mathrm{C}$ приводить до розширення в 15,271 л.

Таке явище з методом заправки на підприємстві несе такі наслідки:

- деформація пластмасових баків;

- псування клапану кришки заливної горловини;

\section{- втрата палива}

- затискання, згин, пошкодження ізоляції при дефрормуванні пластмасових баків.

- зменшення якості контролю за кількістю па-

лива в баці GPS пристроями;

- розрив алюмінієвих, металевих баків.

Стосовно сигналізатора, який вирішить проблеми в зв'язку з розширенням, на початку треба відкалібрувати. Як зазначалось вище об'єм баку трактора NewHolland T8.390 637 л. Пропонуємо 5\% від усього об'єму залишити для розширення палива.

$$
\mathrm{V}_{\text {розш }}=\mathrm{V}_{\text {б }} * 0,05=637 * 0,05=31,85 \text { л }
$$

\begin{tabular}{|c|c|c|c|c|c|}
\hline $\begin{array}{c}\beta, \\
1 /{ }^{\circ} \mathrm{C}\end{array}$ & $\begin{array}{c}\rho, \\
\kappa \Gamma / M^{3}\end{array}$ & $\begin{array}{l}\text { Teм- } \\
\text { пера- } \\
\text { тура } \\
{ }^{\circ} \mathrm{C}\end{array}$ & $\begin{array}{c}\text { Об'єм, } \\
л\end{array}$ & $\begin{array}{l}\text { Tем- } \\
\text { пера- } \\
\text { тура } \\
{ }^{\circ} \mathrm{C}\end{array}$ & $\begin{array}{c}\text { Збыль- } \\
\text { шення } \\
\text { об'єму, } \\
\%\end{array}$ \\
\hline \multirow{31}{*}{$\begin{array}{c}0,79 \\
\times 10^{-3}\end{array}$} & \multirow{31}{*}{860} & 20 & 637,0000 & 20 & 0,0000 \\
\hline & & 21 & 637,5032 & 21 & 0,0790 \\
\hline & & 22 & 638,0069 & 22 & 0,1581 \\
\hline & & 23 & 638,5109 & 23 & 0,2372 \\
\hline & & 24 & 639,0153 & 24 & 0,3164 \\
\hline & & 25 & 639,5201 & 25 & 0,3956 \\
\hline & & 26 & 640,0253 & 26 & 0,4749 \\
\hline & & 27 & 640,5310 & 27 & 0,5543 \\
\hline & & 28 & 641,0370 & 28 & 0,6338 \\
\hline & & 29 & 641,5434 & 29 & 0,7133 \\
\hline & & 30 & 642,0502 & 30 & 0,7928 \\
\hline & & 31 & 642,5574 & 31 & 0,8724 \\
\hline & & 32 & 643,0651 & 32 & 0,9521 \\
\hline & & 33 & 643,5731 & 33 & 1,0319 \\
\hline & & 34 & 644,0815 & 34 & 1,1117 \\
\hline & & 35 & 644,5903 & 35 & 1,1916 \\
\hline & & 36 & 645,0996 & 36 & 1,2715 \\
\hline & & 37 & 645,6092 & 37 & 1,3515 \\
\hline & & 38 & 646,1192 & 38 & 1,4316 \\
\hline & & 39 & 646,6297 & 39 & 1,5117 \\
\hline & & 40 & 647,1405 & 40 & 1,5919 \\
\hline & & 41 & 647,6517 & 41 & 1,6722 \\
\hline & & 42 & 648,1634 & 42 & 1,7525 \\
\hline & & 43 & 648,6754 & 43 & 1,8329 \\
\hline & & 44 & 649,1879 & 44 & 1,9133 \\
\hline & & 45 & 649,7007 & 45 & 1,9938 \\
\hline & & 46 & 650,2140 & 46 & 2,0744 \\
\hline & & 47 & 650,7277 & 47 & 2,1551 \\
\hline & & 48 & 651,2417 & 48 & 2,2358 \\
\hline & & 49 & 651,7562 & 49 & 2,3165 \\
\hline & & 50 & 652,2711 & 50 & 2,3973 \\
\hline
\end{tabular}

де $\mathrm{V}_{\text {розш }}$ - об'єм розширення, л; $\mathrm{V}_{б}$ - об'єм баку,л ;

Таблиця 2. Зміна об'єму при збільшенні температури
Інженерія природокористування, 2019, №4(14), с. 12 - 17 Engineering of nature management, 2019, \#4(14), p. 12 - 17 
Залишається визначити максимальний об'єм заправок, за формулою:

$$
\mathrm{V}_{\text {мах }}=\mathrm{V}_{\text {б }}-\mathrm{V}_{\text {розш }}=637-31,85=605,15 \text { л }
$$

де $\mathrm{V}_{\text {мах }}$ - максимальний об'єм заправок, л.

При об'ємі дизпалива 605,15 л, вихідною напругою датчика рівня палива є 10,5 Вольт. Під'єднавши сигналізатор треба за допомогою перемінного резистора підстроїти вхідну та вихідну напругу, для його спрацюванню при 10,5 Вольт.

Сигналізатор рівня палива складається з мікропроцесора NE 555, конденсатора, трьох підлаштувальних резисторів, звичайного резистора, світлодіода, обмежувача напруги одностороннього та зумера, рис. 3

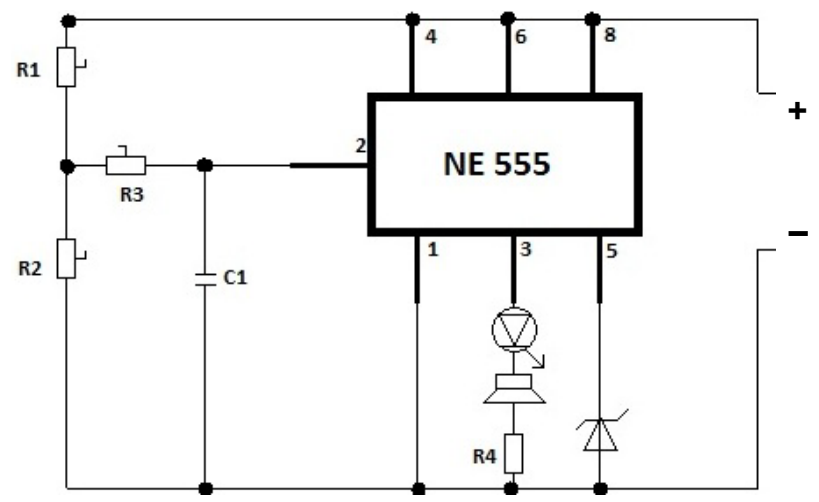

Рис. 3. Схема сигналізатора рівня палива

Працює він від живлення датчика рівня палива, коли напруга зменшиться до 10,5 В, загориться світлодіод та спрацює зумер (подача звукового сигналу). Це означитиме, що заправлено кількість палива з урахуванням розширення при зміні температури в $30^{\circ} \mathrm{C}$.

Висновки.

В статті було проведено аналіз фракторів, що впливають на точність показань датчиків рівня палива. Розглянуті характеристики та конструктивні особливості датчиків рівня палива різних типів. Проаналізовано вплив теплового розширення пального на роботу паливних датчиків. Таке явище з методом заправки на підприємстві несе такі наслідки: деформація пластмасових баків; псування клапану кришки заливної горло- вини; втрата палива, затискання, згин, пошкодження ізоляції при деформуванні пластмасових баків; зменшення якості контролю за кількістю палива в баці GPS пристроями; розрив алюмінієвих, металевих баків. Запропоновано схему сигналізатора рівня палива. Ця схема $є$ оптимальною і не вимагає додаткового втручання в паливну систему.

\section{Література}

1. Датчик рівня палива [Електронний ресурс] // systemsauto.ru. - 2019. - Режим доступу: http://s ystemsauto.ru/fuel/fuel-level-sensor.html.

2. Контроль витрат палива [Електронний ресурс] // Лукаут. - 2019. - Режим доступу: https://loo kout.com.ua/ua/gps-monitoring/kontrol-vitrat-paliva.

3. Паливний контроль [Електронний ресурс] // Мониторинг-Плюс. - 2017. - Режим доступу: https://g ps-plus.com.ua/ukr/pitannya-vidpovid/kontrol-paliva/.

4. Контроль витрат палива [Електронний ресурс] // Єврозвязок. - 2019. - Режим доступу: http: // avtotracker. com. ua /kontrol -vitrat -paliva .html ?language $=u k$.

5. Датчик рівня палива та його ремонт [Електронний ресурс] // Автомотопрофр. - 2019. - Peжим доступу: http://avtomotoprof.ru/obsluzhivaniei- uhod-za-avtomobilem/datchik-urovnya-topliva-i-eg o-remont/.

\section{Reference}

1. Datchyk rivnia palyva [Elektronnyi resurs] // systemsauto.ru. - 2019. - Rezhym dostupu: http://sy stemsauto.ru/fuel/fuel-level-sensor.html.

2. Kontrol vytrat palyva [Elektronnyi resurs] // Lukaut. - 2019. - Rezhym dostupu: https://lookout.c om.ua/ua/gps-monitoring/kontrol-vitrat-paliva.

3. Palyvnyi kontrol [Elektronnyi resurs] // Monytorynh-Plius. - 2017. - Rezhym dostupu: https://gpsplus.com.ua/ukr/pitannya-vidpovid/kontrol-paliva/.

4. Kontrol vytrat palyva [Elektronnyi resurs] // Yevrozviazok. - 2019. - Rezhym dostupu: http://avtot racker.com.ua/kontrol-vitrat-paliva.html?language=uk.

5. Datchyk rivnia palyva ta yoho remont [Elektronnyi resurs] // Avtomotoprof. - 2019. - Rezhym dostupu: http://avtomotoprof.ru/obsluzhivanie-i-uhod-za-avtomo bilem/datchik-urovnya-topliva-i-ego-remont/.

\section{Аннотация}

\section{Повышение точности измерения датчика уровня топлива с помощью сигнализатора уровня топлива}

\section{В.М. Зубко, С.П. Соколик, М.Р. Шевченко}

В статье был проведен анализ факторов, влияющих на точность показаний датчиков уровня топлива. Рассмотрены характеристики и конструктивные особенности датчиков уровня топлива различных типов. На современных автомобилях в качестве датчиков уровня топлива используются 
потенциометрические датчики перемещения. Преимуществами таких датчиков являются простота конструкции, надежность измерений, низкая стоимость. К недостаткам можно отнести наличие подвижных контактов, склонных со временем износа и окислению.

Проанализировано влияние теплового расширения топлива на работу топливных датчиков. Повышение температуры топлива приводит к увеличению его объема, что в свою очередь может привести к повреждению баков и смежных деталей, а также увеличивает погрешность показаний датчиков уровня топлива. Такое явление с методом заправки на предприятии несет следующие последствия: деформация пластмассовых баков; порча клапана крышки заливной горловины; потеря топлива, зажим, изгиб, повреждение изоляции при деформации пластмассовых баков; уменьшение качества контроля за количеством топлива в баке GPS устройствами; разрыв алюминиевых, металлических баков.

Предложена схема сигнализатора уровня топлива. Эта схема является оптимальной и не требует дополнительного вмешательства в топливную систему. Сигнализатор уровня топлива предназначен для заправки топлива до одного и того же уровня при каждой заправке с учетом объема для расширения дизтоплива. Его срабатывание зависит от датчика уровня топлива, в котором, как указано выше, каждому значению уровня топлива в баке соответствует определенный сигнал датчика и изменение напряжения на потенциометре. Диапазон напряжения датчика уровня топлива от 0 до 12 В.

Ключевые слова: топливо, расход топлива, датчик уровня топлива, точность измерения, тепловое расширение, сигнализатор уровня топлива.

Abstract

\section{Improving the accuracy of measuring the fuel level sensor using a fuel level indicator}

\section{V.M. Zubko, S.P. Sokolik, M.R. Shevchenko}

The article analyzed the factors affecting the accuracy of the fuel level sensor readings. The characteristics and design features of various types of fuel level sensors are considered. In modern cars, the potentiometric displacement sensors are used as fuel level sensors. The advantages of such sensors are simplicity of construction, reliability of measurements, low cost. Disadvantages include the presence of mobile contacts, inclined with the time of wear and oxidation.

The effect of thermal expansion of fuel on the operation of fuel sensors is analyzed. An increase in the temperature of the fuel leads to an increase in its volume, which can lead to damage tanks and adjacent parts and also increases the error of the readings of fuel level sensors. Such a phenomenon with the method of refueling in an enterprise has the following consequences: deformation of plastic tanks; damage valve filler cap; loss of fuel, clamping, bending, insulation damage during deformation of plastic tanks; reducing the quality of control over the amount of fuel in the tank GPS devices; break aluminum, metal tanks.

The scheme of the fuel level indicator is proposed. This scheme is optimal and does not require additional intervention in the fuel system. The fuel level indicator is designed to refuel the fuel to the same level at each refueling, taking into account the volume for the expansion of diesel fuel. Its operation depends on the fuel level sensor, in which, as indicated above, each value of the fuel level in the tank corresponds to a certain sensor signal and a change in voltage at the potentiometer. The voltage range of the fuel level sensor is from 0 to $12 \mathrm{~V}$.

Keywords: fuel, fuel consumption, fuel level sensor, measurement accuracy, thermal expansion, fuel level indicator.

Бібліографічне посилання/ Bibliography citation: Harvard

Zubko, V., Sokolik, S. and Shevchenko, M. (2019). Improving the accuracy of measuring the fuel level sensor using a fuel level indicator. Engineering of nature management, (3(13), pp. 30 - 35.

Подано до редакції / Received: 10.06.2019

ISSN 2311-1828

http://enm.khntusg.com.ua
Інженерія природокористування, 2019, №4(14), с. 12 - 17

Engineering of nature management, 2019, \#4(14), p. 12 - 17 